\title{
Viral therapies for glioblastoma and high-grade gliomas in adults: a systematic review
}

\author{
Joshua L. Wang, MD, ${ }^{1}$ Kristen M. Scheitler, MD, ${ }^{2}$ Nicole M. Wenger, MD, ${ }^{3}$ and J. Bradley Elder, MD ${ }^{1}$ \\ ${ }^{1}$ Department of Neurological Surgery, The Ohio State University Wexner Medical Center, Columbus, Ohio; ${ }^{2}$ Department of \\ Neurologic Surgery, Mayo Clinic, Rochester, Minnesota; and ${ }^{3}$ Department of Neurosurgery, University of Maryland, Baltimore, \\ Maryland
}

\begin{abstract}
OBJECTIVE High-grade gliomas (HGGs) inevitably recur and progress despite resection and standard chemotherapies and radiation. Viral therapies have emerged as a theoretically favorable adjuvant modality that might overcome intrinsic factors of HGGs that confer treatment resistance.
\end{abstract}

METHODS The authors present the results of systematic searches of the MEDLINE and ClinicalTrials.gov databases that were performed for clinical trials published or registered up to July 15, 2020.

RESULTS Fifty-one completed clinical trials were identified that made use of a virus-based therapeutic strategy to treat HGG. The two main types of viral therapies were oncolytic viruses and viral vectors for gene therapy. Among clinical trials that met inclusion criteria, 20 related to oncolytic viruses and 31 to gene therapy trials. No oncolytic viruses have progressed to phase III clinical trial testing, although there have been many promising early-phase results and no reported cases of encephalitis or death due to viral therapy. Three phase III trials in which viral gene therapy was used have been completed but have not resulted in any FDA-approved therapy. Recent efforts in this area have been focused on the delivery of suicide genes such as herpes simplex virus thymidine kinase and cytosine deaminase.

CONCLUSIONS Decades of research efforts and an improving understanding of the immunomodulatory effects of viral therapies for gliomas are informing ongoing clinical efforts aimed at improving outcomes in patients with HGG. The available clinical data reveal varied efficacy among different virus-based treatment strategies.

https://thejns.org/doi/abs/10.3171/2020.11.FOCUS20854

KEYWORDS glioblastoma; oncolytic viruses; oncolytic virotherapy; genetic therapy; immunomodulation

$\mathrm{G}$ LIOBLASTOMA (GBM) is the most common primary brain malignancy ${ }^{1}$ and is invariably fatal despite maximal safe resection, followed by adjuvant chemotherapy and radiation. ${ }^{2}$ The median survival remains less than 15 months due to the infiltrative nature of these tumors (making complete resection impossible), sequestration behind the blood-brain barrier (BBB), immuneprivileged status of the CNS, and eventual treatment resistance, thereby underscoring a need for novel treatments that extend survival.

Theoretically, viral therapies combat these characteristics through direct tumoricidal effects and generation of anticancer inflammatory responses that overcome the immunosuppressive high-grade glioma (HGG) and GBM microenvironments. ${ }^{3}$ The concept of virus therapies for cancer was established in 1912, when a woman's cervical cancer regressed after she received an attenuated rabies vaccine; ${ }^{4}$ this connection between viral infection and cancer regression was anecdotally reported for several decades until a better understanding of viral genomics and engineering ushered in the modern era of viral therapies in the early 1990s. Martuza and colleagues engineered the first herpes simplex virus (HSV) mutants for oncolytic purposes in $1991,{ }^{5}$ and these were shortly followed by an oncolytic adenovirus mutant in $1996 .{ }^{6}$ Since then, viral therapies have expanded to include dozens of different species and strains of viruses, which are broadly categorized into two overlapping strategies: replicationcompetent oncolytic viruses (OVs) and gene therapy viral vectors. Current clinical applications of these viruses are typically delivered into the tumor or resection cavity by stereotactic injection, free-hand injection, or convectionenhanced delivery (CED), bypassing the BBB. ${ }^{7-10}$

OVs are replication-competent viruses that either are

ABBREVIATIONS Ad5 = human adenovirus serotype 5; BBB = blood-brain barrier; $\mathrm{CAR}=$ coxsackie and adenovirus receptor; $\mathrm{CDA}=$ cytosine deaminase; CED = convection-enhanced delivery; elF2 $\alpha$ = eukaryotic initiation factor; GBM = glioblastoma; HGG = high-grade glioma; HSV = herpes simplex virus; HSV-tk = HSV thymidine kinase; $\mathrm{MTD}=$ maximum tolerated dose; OS = overall survival; OV = oncolytic virus; $\mathrm{PFS}=$ progression-free survival; PPE = preproendothelin.

SUBMITTED September 30, 2020. ACCEPTED November 9, 2020.

INCLUDE WHEN CITING DOI: 10.3171/2020.11.FOCUS20854. 
genetically engineered to selectively target tumor cells while sparing normal cells or are naturally onco-selective. Inside a tumor cell, the OV replicates, causing tumor cell lysis and subsequent release of viral progeny that may further infect surrounding tumor cells. Tumor cell lysis also releases tumor neoantigens that stimulate both the innate and adaptive immune system.11,12 This multiplication of the initial dose is unique to OVs among all forms of medical treatments and theoretically requires a lower inoculum compared to replication-incompetent vectors.

Alternatively, gene therapy viral vectors can be used to deliver genetic material specifically into tumor cells and to harness cellular transcription and translation machinery to produce desired proteins. These products may convert nontoxic prodrugs to toxic forms, or may function as immunomodulatory proteins and cytokines that activate the immune system against tumor cells.

Although early viral therapies fell squarely into the oncolytic or gene therapy categories, progress in viral technology has created numerous viruses that have characteristics of both groups to take advantage of the relative benefits of both strategies. OVs such as DNX-2440 and M032 transduce immune stimulatory genes (OX40L and $I L-12$, respectively) into infected tumor cells to promote antitumor immune responses in the tumor environment. ${ }^{13}$ The gene therapy vector Toca 511 is replication competent, allowing it to expand its tumoricidal reach beyond the initial injection dose and volume. ${ }^{14-16}$

More than 2 decades of clinical trials with virus-based therapies have yielded promising early results. This systematic review was performed to provide a comprehensive overview of completed and ongoing clinical trials investigating viral therapies for HGG in adults.

\section{Methods}

\section{Search Strategy and Study Selection}

The systematic search of the MEDLINE database was performed on July 15, 2020. MeSH headings were queried to identify all clinical study citations indexed under "glioma" or "brain neoplasm" and including at least one of the following MeSH headings: "viruses," "oncolytic viruses," "oncolytic virotherapy," "genetic therapy," "vaccines," or "immunomodulation." Keyword searches were performed to identify any relevant studies that were not captured in the MeSH heading search due to incomplete or alternative MeSH indexing. Keywords used included "glioma," "glioblastoma," "viral therapy," "oncolytic virus," "gene therapy," and "viral." Publication types were limited to "clinical trial" or "clinical study" and their subtypes. Ongoing or completed studies without published results were identified on clinicaltrials.gov via keyword searches using the same keywords as above. Additional relevant studies were identified during the assessment of full texts and were added to the review.

Studies collected from the search were screened individually and included in the final review only if 1) the study investigated the administration of virus therapy to treat adult gliomas, and 2) the study was designed as a prospective clinical trial, using human subjects. Because treatment of GBMs and HGGs faces very similar chal- lenges, and many clinical trials have included both patients with GBM and those with HGG, trials including patients with HGG were included in this literature review.

\section{Data Collection}

Data were collected from these studies individually by the investigators, with consensus regarding data reached by at least 3 authors. Variables collected from these studies included the following: type and dose of virus and drugs administered, experimental design and treatment groups, primary and secondary outcome measures, safety data, and survival outcomes.

\section{Results}

A total of 51 completed clinical trials investigating viral therapies for gliomas were identified using the search and selection algorithm ${ }^{17}$ in Fig. 1. Additionally, 16 ongoing trials were identified within published manuscripts or through searches on clinicaltrials.gov. Among clinical trials that met inclusion criteria, 20 were related to OVs and 31 to gene therapy trials. The accumulation of clinical trials on viral therapies for HGG over time is depicted in Fig. 2. Those viruses that share properties of both oncolytic and gene therapy vectors are discussed below in the category that they more closely resemble and/or alongside their respective siblings and predecessors.

\section{Oncolytic Viruses}

Currently, most available clinical data regarding OVs for GBMs and HGGs are from phase I trials; no trial has progressed to phase III. Most trials have been performed for recurrent or progressive rather than newly diagnosed HGG, except for one completed and two ongoing trials (ISRCTN70044565, NCT03072134). Serious adverse events such as encephalitis or death have not been reported. A comprehensive summary of completed and ongoing OV trials can be found in Tables 1 and 2, respectively.

\section{HSV-1}

HSV type 1 (HSV-1) is a large, double-stranded DNA human pathogen. It is perhaps the best studied of the OVs, given its neurotropism, safety profile, and genomic modifiability. The HSV-1 genes for neurovirulence and for oncolysis are distinct, allowing for genetic control that selects for oncolysis while eliminating untargeted nonspecific neurovirulence. ${ }^{7}$ The first iteration of HSV-1 investigated for glioma therapy involved a mutated HSV thymidine kinase $(H S V$ - $t k)$ gene, dlstpk, which attenuated neurovirulence but rendered the virus insensitive to acyclovir and ganciclovir, thus precluding its use in clinical trials..$^{5}$ This early work, however, led to the development of HSV-1 mutants that exhibited reduced neurotoxicity while retaining their oncolytic ability. The first generation of clinical oncolytic HSV-1 mutants (HSV1716) had deletions of both copies of the viral $\gamma_{1} 34.5$ gene, which is essential for neurovirulence by dephosphorylating eukaryotic initiation factor (eIF2 $\alpha$ ) and restoring protein synthesis. Later-generation HSV-1 mutants built on the $\gamma_{1} 34.5$ deletions by adding further mutations. For example, disruption 


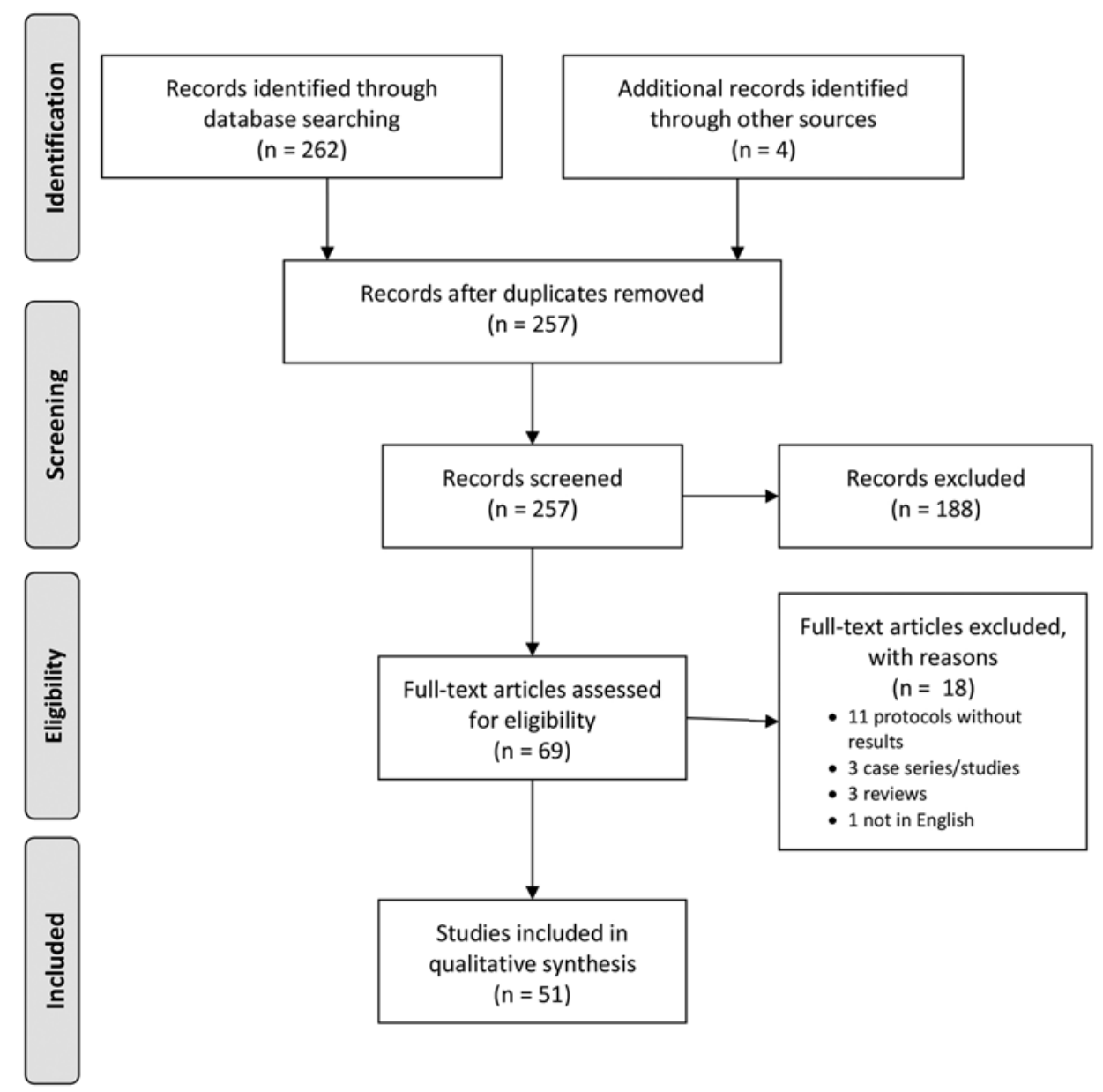

FIG. 1. PRISMA 2009 study selection flow diagram.

of $U_{L} 39$ (which encodes ICP6, ribonucleic reductase) prevents reactivation of DNA replication machinery in postmitotic cells (e.g., neurons) ${ }^{7}$ and increases viral sensitivity to acyclovir ${ }^{19}$ while DNA replication persists in actively dividing tumor cells.

Three phase I trials investigating HSV1716 have been completed for 33 total patients with HGG, demonstrating the following: 1) feasibility of stereotactic intratumoral inoculation; ${ }^{20}$ 2) viral replication in tumor cells; ${ }^{21}$ and 3 ) safety of peritumoral resection cavity injections..$^{18}$ Treatment with virus was well tolerated without serious adverse events, and a survival of 14-25 months was observed in 7 patients (5 recurrent, 2 newly diagnosed). In one trial, 12 patients received intratumoral inoculation followed by tumor resection 4-9 days later. Assays for viral replication within tumor cells were positive at inoculation sites in 10 patients and at distal tumor sites in 4 patients.

G207 is a second-generation, $\gamma_{1} 34.5$-deleted HSV-1 with inactivated $U_{L} 39$. The safety profile is improved by inactivation of the $U_{L} 39$ gene. However, neurovirulence and replicative ability are further attenuated, thus requiring higher doses of G207 to reach infective and oncolytic levels similar to those of HSV1716. Three phase I trials have been conducted for 38 total patients and have demon- strated the safety of intratumoral and peritumoral resection cavity injections, tolerability of 2 injections in a week, HSV replication in tumor cells, and synergistic effect of concurrent radiation. ${ }^{22-24}$ Similar to the HSV1716 trials, the maximum tolerated dose (MTD) was not achieved, with or without radiation the following day. Radiographic regression and pathological evidence of viral replication and antitumor activity were observed in the first two trials. Additionally, use of G207 in conjunction with radiation showed potential for clinical response, with a median overall survival (OS) of 7.5 months. Two trials using G207 for pediatric brain tumors are ongoing.

Additional strategies to improve oncolytic HSV-1 mutants currently under clinical investigation include the following: deletion of the ICP47 gene to increase major histocompatibility complex class I antigen presentation and enhance viral replication (G47A, JPRN-UMIN000002661, JPRN-UMIN000015995); ${ }^{25,26}$ transduction of the $I L-12$ gene to help activate type 1 cell-mediated anticancer immune activity (M032, NCT02062827); ${ }^{13}$ and reinsertion of one copy of $\gamma_{1} 34.5$ under a nestin promoter to overcome host-cell hyperphosphorylation of eIF $2 \alpha$, which leads to decreased protein synthesis and poor $\gamma_{1} 34$.5-deleted virus growth (rQNestin34.5v.2, NCT03152318). ${ }^{27,28}$ 


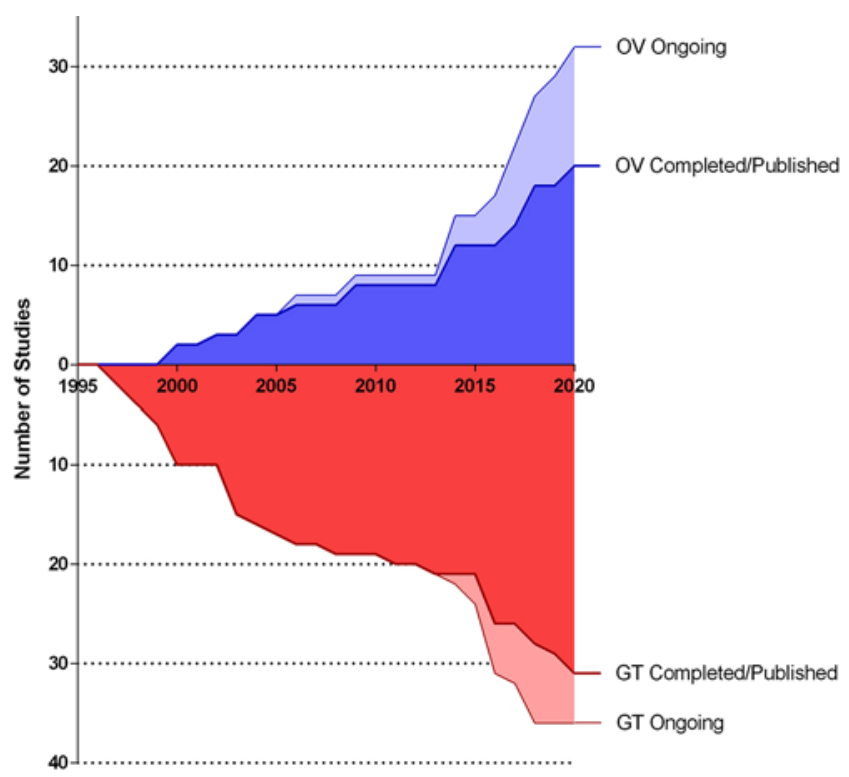

FIG. 2. Graph showing cumulative viral therapy trials for HGG over time. Curves plotted by publication year, or if completed but results not yet published, by study completion year. Additionally, ongoing trials that have not yet been published were plotted above or below the completed trials curves based on the start date listed on the official clinical trial registry record (clinicaltrials.gov or WHO International Clinical Trials Registry Platform). GT = gene therapy virus.

\section{Adenovirus}

Human adenovirus serotype 5 (Ad5) is a human pathogen that normally infects human cells using the coxsackie and adenovirus receptor (CAR), a step that is necessary for internalization and subsequent infectivity of the virus. However, CAR expression is markedly reduced on glioma tumor cells, and various genetic modifications that allow Ad5 to selectively infect tumor cells in a CAR-independent fashion have been studied. These "conditionally replicating adenoviruses" (CRAds) are attenuated by E1A and E1B gene deletions. DNX-2401 (previously Delta-24-RGD) has a 24-base pair deletion in the Ad5 E1A gene, which inhibits E1A protein binding to retinoblastoma protein. Thus, DNX-2401 selectively replicates in tumor cells that harbor retinoblastoma mutations. In a phase I dose-escalation trial for intratumoral injection of DNX-2401, 37 patients with recurrent HGG received either a single intratumoral inoculation (group $\mathrm{A}, \mathrm{n}=25$ ) or intratumoral inoculation followed by resection and peritumoral injections (group $\mathrm{B}, \mathrm{n}=12$ ). In group $\mathrm{A}$, tumor reduction occurred in 18 patients, with a median OS of 9.5 months, and 5 patients survived more than 3 years. Group $B$ had a median OS of 13.0 months, and 2 patients survived for 2 years. ${ }^{29}$ Trials investigating CED of DNX-2401 (phase I/II, NCT00805376), and synergies of intratumoral DNX with temozolomide (phase I, NCT01956734) and with interferon-gamma (phase Ib, NCT02197169) have been completed, but results are not yet published. A phase II trial investigating intratumoral DNX-2401 followed by intravenous pembrolizumab (CAPTIVE/KEYNOTE-192, NCT02798406) and a phase I trial evaluating the feasibility and safety of intraarterial delivery of allogeneic bone marrow-derived mesenchymal stem cells ${ }^{30}$ loaded with DNX-2401 (NCT03896568) are ongoing. DNX-2440 is a newer virus based on DNX-2401, but additionally transduces the OX40 ligand $(O X 40 L)$ gene. Expression of $O X 40 L$ on tumor cell surfaces activates T cells and generates antitumor immune response. DNX-2440 is currently undergoing a phase I trial (NCT03714334).

\section{Other OVs}

Reoviruses, paramyxoviruses, parvoviruses, and poliovirus have all demonstrated safety without MTDs in phase I trials, of which some are currently in the phase II trial stage (Tables 1 and 2).

\section{Gene Therapy}

Viral vectors can deliver various types of cytotoxic and/or immunostimulatory genes to tumor cells, the most common anticancer strategy being "suicide" genes that express enzymes that convert a systemically delivered prodrug to active cytotoxic compounds. ${ }^{31}$ Summaries of completed and ongoing clinical trials in which viral gene therapy is being used are provided in Table 3 and Table 4, respectively.

\section{Thymidine Kinase}

The best-studied suicide gene is $H S V$ - $t k$, the enzyme product of which converts systemically delivered ganciclovir or acyclovir to monophosphate forms, which are then converted to triphosphate forms by cellular kinases. The triphosphate forms inhibit DNA synthesis, resulting in S-phase delay, G2M-phase arrest, and subsequent initiation of tumor cell apoptosis. . $^{3,33}$

The phase III GTI-115 study published in 2000 evaluated a retroviral vector delivering HSV-tk in newly diagnosed patients with $\mathrm{HGG} .{ }^{34}$ All patients received standard radiation after tumor resection. Additionally, half $(n=124)$ of the 248 patients were randomized to receive peritumoral resection cavity injections of retroviral vector-producing cells derived from murine fibroblasts at the time of tumor resection, followed by daily ganciclovir for 2 weeks starting on postoperative day 14. There were no differences in median progression-free survival (PFS) between the experimental and control groups (180 vs 183 days) or median OS (365 vs 354 days).

The ASPECT phase III trial (EudraCT 2004-00046428) completed in 2008 used adenoviral vectors (sitimagene ceradenovec) expressing HSV-tk. ${ }^{35}$ All 236 patients underwent resection, and 119 patients were randomized to receive peritumoral resection cavity injections of adenovirus, followed by daily intravenous ganciclovir for 14 days starting on postoperative day 5. Patients who received adenovirus demonstrated improvement in the primary outcome measure of composite of time to death or reintervention (corrected for temozolomide use) (308 vs 268 days), although there was no difference in the secondary endpoint, OS (497 vs 452 days). The investigators noted that increased adenovirus-neutralizing antibodies (3, 6, and 12 months after surgery) were associated with increased efficacy of treatment, potentially suggesting a bystander effect of adenovirus enhancement of an antitumor immune response. 


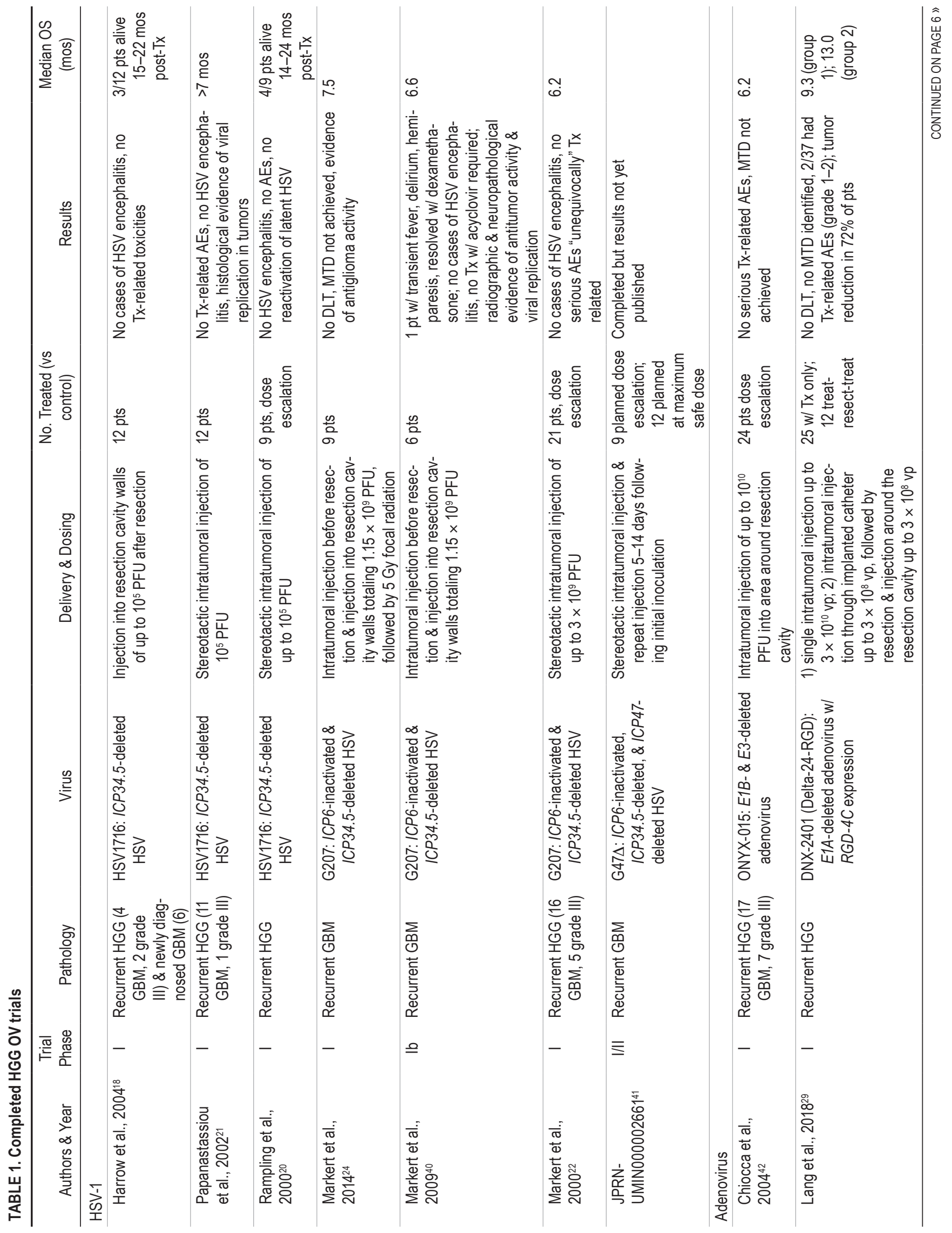




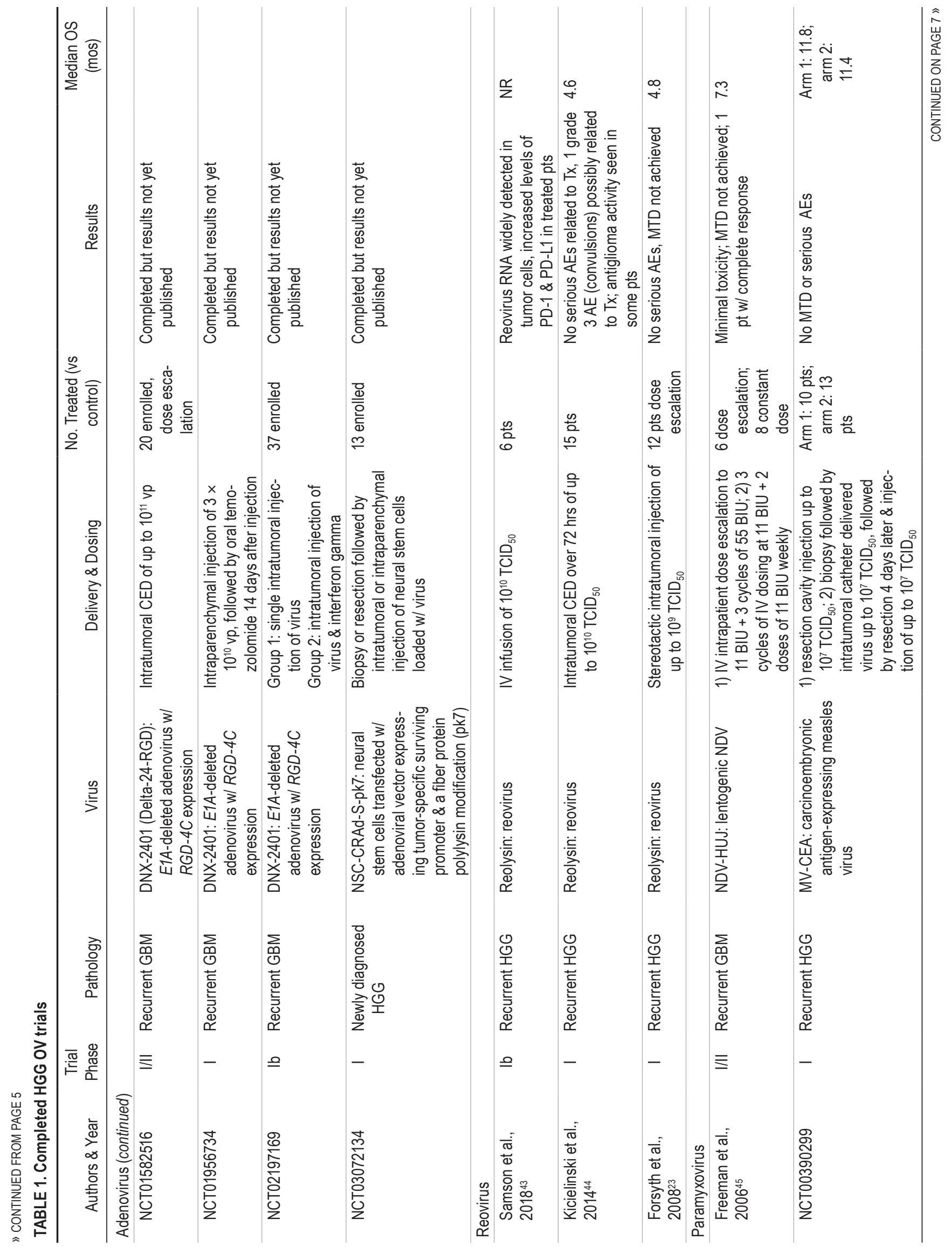


Two phase II trials using HSV-tk demonstrated promising results. ${ }^{36,37}$ The first (NCT00589875) enrolled 48 newly diagnosed patients with HGG and 134 matched standard-of-care controls at a separate institution. The 48 study patients received peritumoral resection cavity injections of an adenoviral vector expressing $H S V$ - tk (aglatimagene besadenovec) at the time of tumor resection, followed postoperatively with valacyclovir. ${ }^{36}$ Outcome measures that were significantly improved for the treatment group included median OS (17.1 vs 13.5 months) and median PFS (8.1 vs 6.5 months). Investigators noted that patients who underwent gross-total resection benefited most from the gene therapy, with median OS values of 25.0 and 16.9 months for those in the experimental and control groups, respectively. In contrast, there was no survival benefit for those receiving subtotal resection (13.5 vs 12.5 months), which investigators posited was due to the immunosuppressive capabilities of remaining tumor that may mask the effect of gene-mediated cytotoxicity or viral-mediated immune stimulation. The authors further suggested that the addition of checkpoint inhibitors may be important in overcoming this immunosuppression in patients receiving subtotal resection.

The other phase II trial (NCT00870181) randomized 43 patients with recurrent HGG to receive intraarterial cerebral injections of an adenoviral vector expressing HSV-tk, followed by ganciclovir in addition to standard of care ( $\mathrm{n}$ $=22 ; 14$ GBM, 8 WHO grade III) or by standard of care alone $\left(\mathrm{n}=22\right.$; 18 GBM, 4 WHO grade III) ${ }^{37}$ Patients receiving adenovirus had increased PFS at 6 months $(54.5 \%$ vs $13.6 \%$, respectively), median PFS (29.6 vs 8.4 weeks, respectively), and median OS (45.4 vs 14.3 weeks, respectively) compared to controls.

\section{Cytosine Deaminase}

Another gene therapy strategy involves delivery of cytosine deaminase (CDA), followed by systemic administration of 5-fluorocytosine (5-FC). In transduced cells, CDA converts nontoxic 5-fluorocytosine into toxic 5-fluorouracil (5-FU), resulting in tumor cell death. Toca 511 (vocimagene amiretrorepvec) is a replicating retroviral vector expressing CDA, which, in contrast to replication-deficient vectors, could infect tumor cells more extensively over time and increase expression levels of the CDA enzyme, and had shown promising early-phase results in recurrent HGG. In completed phase I dose-escalation trials, stereotactic administration of Toca 511 intratumorally (NCT01156584) ${ }^{15}$ and into peritumoral resection cavity walls (NCT01470794) ${ }^{16}$ demonstrated favorable safety and survival profiles (median OS 11.9-13.6 months). Durable and complete responses were noted in 6 of 53 patients receiving peritumoral injections. Despite promising early-phase results and a number of ongoing or unpublished phase I trials investigating Toca 511, the randomized, open-label phase III trial (NCT02414165) of 271 patients failed to meet its primary outcome of OS compared to standard of care (11.1 months vs 12.2 months, HR 1.06; $\mathrm{p}=0.62$ ) and demonstrated no significant difference in any secondary endpoints between the two arms..$^{14}$ Full peer-reviewed phase III data have not yet been published, but the failure of the phase III trial effectively ended other investigation into Toca 511. 


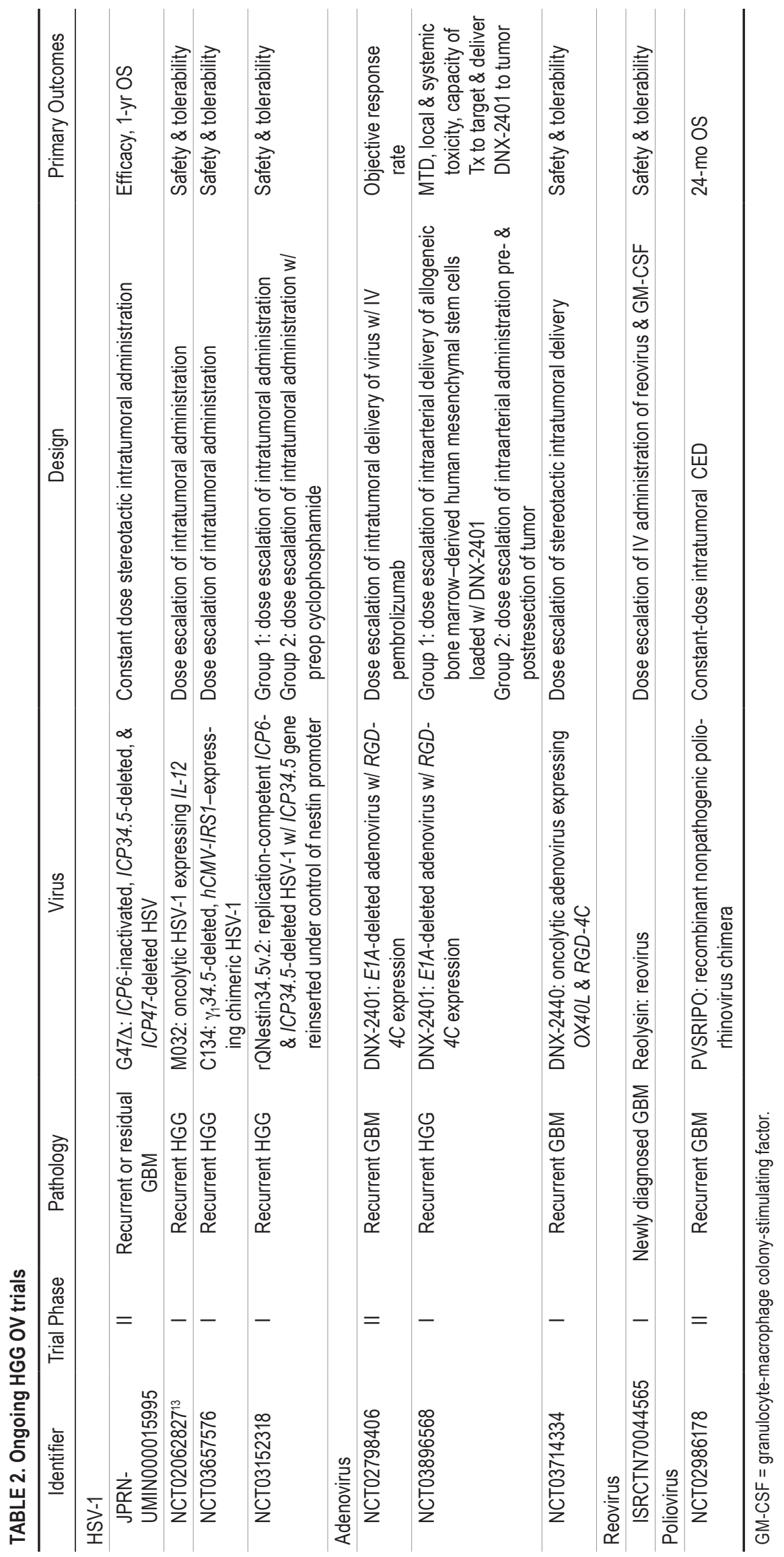




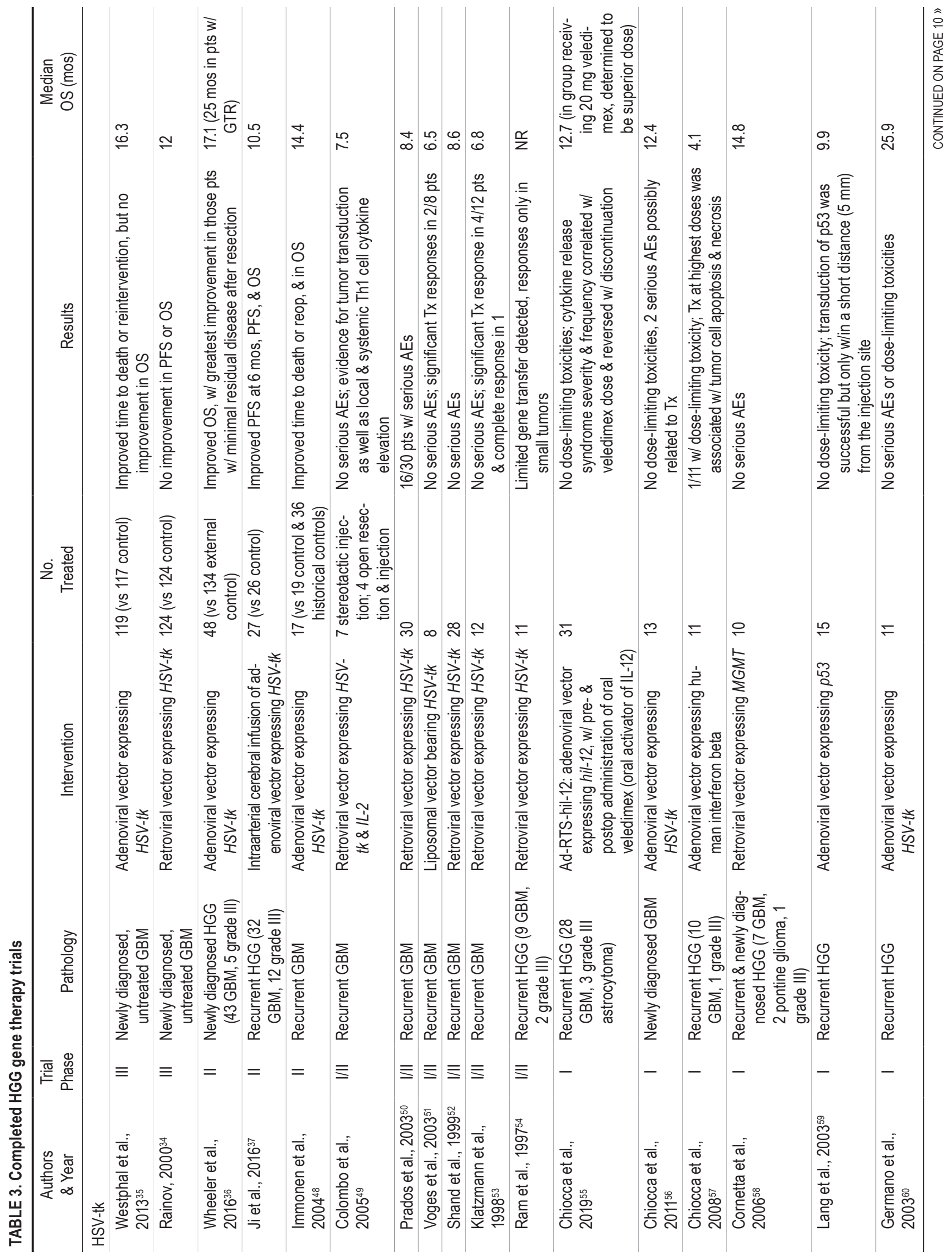




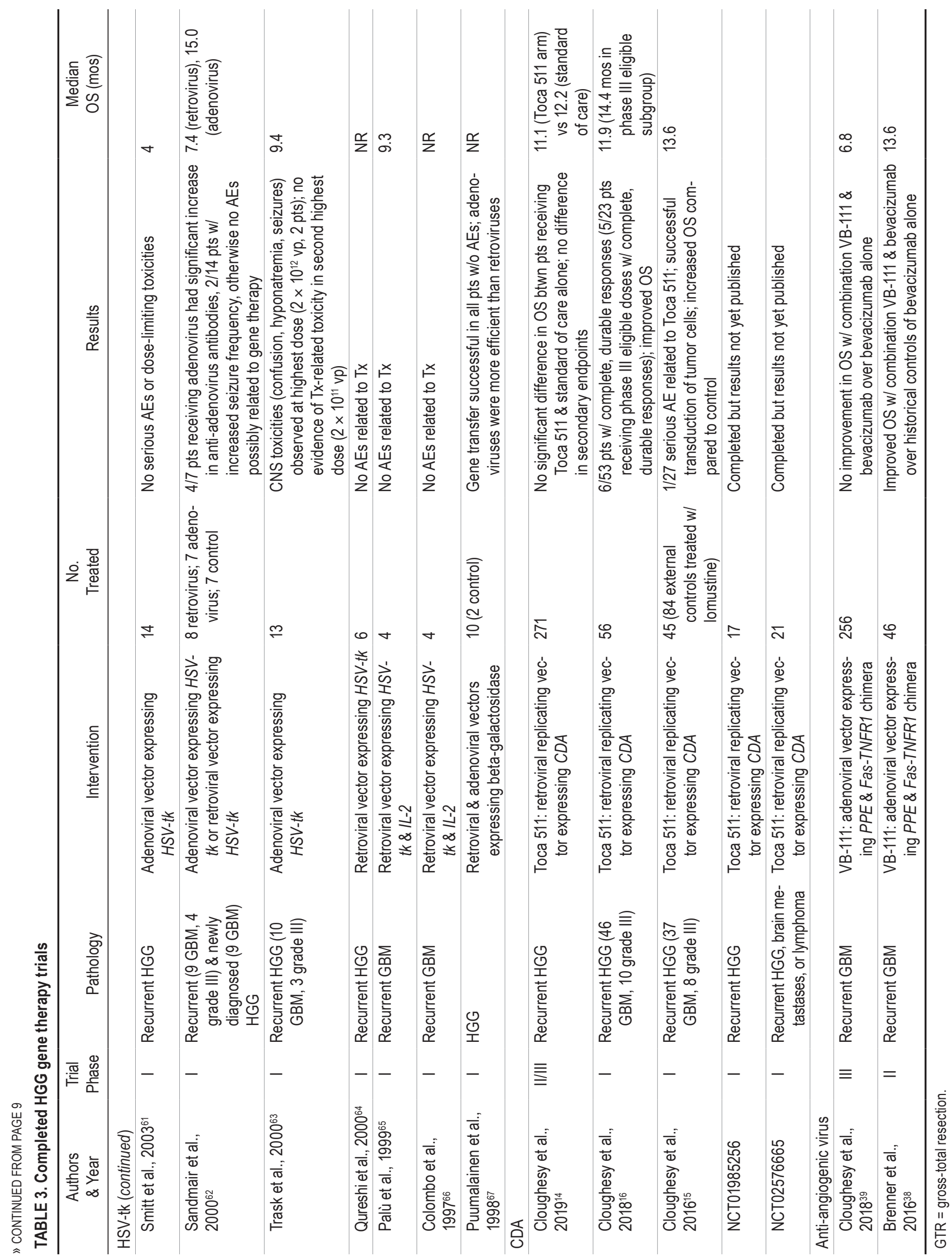


TABLE 4. Ongoing HGG gene therapy trials

\begin{tabular}{|c|c|c|c|c|}
\hline Identifier & $\begin{array}{l}\text { Trial } \\
\text { Phase }\end{array}$ & Pathology & Virus & Design \\
\hline NCT02598011 & $\mathrm{lb}$ & $\begin{array}{l}\text { Newly diag- } \\
\text { nosed HGG }\end{array}$ & $\begin{array}{l}\text { Toca 511: retroviral replicating vector ex- } \\
\text { pressing CDA }\end{array}$ & $\begin{array}{l}\text { Peritumoral resection cavity injections of Toca } 511 \mathrm{w} / \text { dose } \\
\text { escalation of Toca FC, in combination w/ standard-of-care } \\
\text { chemoradiation \& temozolomide }\end{array}$ \\
\hline NCT01811992 & I & $\begin{array}{l}\text { Newly diag- } \\
\text { nosed HGG }\end{array}$ & $\begin{array}{l}\text { Ad-hCMV-tk \& Ad-hCMV-Flt3L: adenoviral } \\
\text { vectors delivering HSV1-tk \& Flt3L }\end{array}$ & Dose escalation of peritumoral resection cavity injections \\
\hline NCT03679754 & 1 & $\begin{array}{l}\text { Recurrent } \\
\text { GBM }\end{array}$ & $\begin{array}{l}\text { Ad-RTS-hil-12: adenoviral vector expressing } \\
\text { hil-12 }\end{array}$ & $\begin{array}{l}\text { Peritumoral resection cavity injections, w/ oral veledimex } \\
\text { (expansion substudy of NCT02026271) }\end{array}$ \\
\hline NCT03636477 & 1 & $\begin{array}{l}\text { Recurrent } \\
\text { GBM }\end{array}$ & $\begin{array}{l}\text { Ad-RTS-hil-12: adenoviral vector expressing } \\
\text { hil-12 }\end{array}$ & $\begin{array}{l}\text { Peritumoral resection cavity injections, w/ nivolumab \& oral } \\
\text { veledimex (expansion substudy of NCT02026271) }\end{array}$ \\
\hline NCT00031083 & 1 & $\begin{array}{l}\text { Recurrent } \\
\text { HGG }\end{array}$ & $\begin{array}{l}\text { BG00001: adenoviral vector expressing } \\
\text { interferon beta }\end{array}$ & Dose escalation of intratumoral injection (study suspended) \\
\hline NCT03294486 & $\mathrm{I} / \mathrm{lla}$ & $\begin{array}{l}\text { Recurrent } \\
\text { GBM }\end{array}$ & $\begin{array}{l}\text { TG6002: TK- \& RR (ribonucleotide } \\
\text { reductase)-deleted vaccinia viral vector } \\
\text { expressing FCU1 }\end{array}$ & $\begin{array}{l}\text { Phase I: dose escalation of IV administration; phase Ila: IV ad- } \\
\text { ministration at dose recommended based on phase I results }\end{array}$ \\
\hline NCT04406272 & II & $\begin{array}{l}\text { Recurrent } \\
\text { GBM }\end{array}$ & $\begin{array}{l}\text { VB-111: adenoviral vector expressing PPE \& } \\
\text { Fas-TNFR1 chimera }\end{array}$ & $\begin{array}{l}\text { Experimental arm A: IV VB-111 before \& after resection; } \\
\text { experimental arm B: IV VB-111 after resection; control arm: } \\
\text { placebo \& standard-of-care resection }\end{array}$ \\
\hline
\end{tabular}

\section{Angiogenesis}

VB-111 is a nonreplicating, E1-deleted adenoviral vector expressing a modified murine preproendothelin (PPE) promoter and a proapoptotic Fas-chimera transgene composed of tumor necrosis factor receptor -1 and the intracellular signaling domain of Fas. This construct provides strong cell death signaling with targeting specificity to angiogenic vessels in tumor tissue. Phase II data $(\mathrm{NCT} 01260506)^{38}$ demonstrated that in patients with recurrent GBM, those who received VB-111 both prior to and following further progression and who also received concurrent bevacizumab after further progression (i.e., they had been primed with VB-111 for bevacizumab treatment) had significantly increased PFS (90 days) and OS (414 days) compared to those in the other two groups. The other groups were composed of patients who did not receive VB-111 concurrently with bevacizumab and patients who did receive VB-111 concurrently with bevacizumab but not prior to bevacizumab therapy (PFS 60 vs 63 days, respectively; OS 223 vs 142 days, respectively). However, the phase III trial did not include the priming group that demonstrated improved PFS and OS in the phase II trial. Thus, the phase III trial failed to demonstrate survival benefit of VB-111 in conjunction with bevacizumab over bevacizumab alone (NCT02511405). ${ }^{39}$

\section{Discussion}

The future of virus-based therapies for GBM will probably see progression of the viral strategies discussed here into later-phase trials, and newer oncolytic and gene therapy strategies entering the early-phase clinical trial pipeline. Since the first clinical trial examining viruses for HGG treatment published more than 2 decades ago, the number of virus candidates and studies has drastically increased. As viral technology progresses, more viruses are being created that share attributes and capabilities of previously strictly oncolytic or gene therapy viruses. OVs loaded with genes such as $O X 40 L$ and $I L-12^{13}$ augment and expand the antitumor response already generated by tumor cell death. Replication-competent gene therapy vectors carrying suicide genes ${ }^{14-16}$ spread beyond their injection volume and provide an effective dose higher than their initial inoculum. Although there are many approaches to viral therapy development, those harnessing the full potential of virus replication and viral gene delivery together may overcome the challenges that either strategy faces alone (such as limitations in virus spread and immune sequestration and suppression by tumor cells).

Owing to much of the early research, viral therapies are increasingly recognized as well tolerated with few adverse side effects. In the majority of early-phase trials MTDs were not achieved, and when toxicities were noted, most were related to the underlying disease, such as headache, seizure, or progressive neurological deficit. Potential systemic responses to viral infection, such as fever and malaise, were mild and resolved spontaneously. Additionally, studies in which virus was injected into the "normal" brain parenchyma surrounding the resection cavities did not show an increased rate of adverse events or toxicities such as cerebritis, suggesting that nonspecific viral infection of normal brain parenchyma or direct toxicity of the injection is not a frequent event.

Although several delivery methods have been studied, no single method has been standardized. Intratumoral injection and peritumoral resection cavity injections are the simplest and most studied routes of administration, offer direct inoculation of the affected tissue, and are well tolerated. However, they are constrained by their invasive nature, single dose, limited penetration and distribution of virus (especially with replication-deficient viruses), potential for reflux out along the injection tract, and (in the case of free-hand and/or peritumoral injections) lack of unifor- 
mity of administration. CED allows for continuous infusion of virus and a theoretically increased volume of tissue covered, but remains limited by its invasive technique. CED is a mechanism of interest to both neurosurgeons and engineers, and optimization of current CED components is subject to ongoing investigation. Systemic administration of virus could bypass the need for neurosurgical intervention but faces the challenges of crossing the BBB and possible destruction by the systemic immune system, for which cell-based delivery of virus is being developed. Replication-competent virus strategies may have more applications given typical single-dosing parameters.

Over the course of these studies, investigators have gained increased understanding of the immune response to virus administration that leads to additional antitumor effects. HGGs produce highly immunosuppressive tumor microenvironments, with high levels of transforming growth factor- $\beta$, IL-10, and prostaglandin E2, and these lesions recruit immunosuppressive T-regulatory lymphocytes and M2-phenotype macrophages. Many studies have shown that viral infection of the tumor generates local and systemic inflammatory responses, despite the immunosuppressed nature of patients with HGG, as evidenced by increased numbers of local $\mathrm{T}$ lymphocytes, natural killer cells, macrophages, and circulating Th1 cell-related cytokines. Additionally, most of these studies have been performed in patients with recurrent HGG, who already had received systemic therapies that further immunosuppression, such as chemotherapies, radiation, and corticosteroids. Future studies must clarify the relationship between the type of virus administered and immune response generated, and whether there are optimal combinations for certain tumors or patients.

Finally, although checkpoint inhibitors have been effective in the management of melanoma and other immunogenic malignancies, preliminary studies have not shown a definitive benefit of checkpoint inhibitors alone for primary brain malignancies. Recent preclinical studies in HGG have shown that viral therapies may augment the response to checkpoint inhibition. Thus, the combined use of viral therapy and checkpoint inhibitors is of particular interest for continued clinical investigation.

\section{Conclusions}

Viral therapies for HGG have been subject to trials for more than 2 decades, without a novel standard-of-care treatment. However, recent work with oncolytic and gene therapy viruses has benefited from improved understanding of synergistic effects with standard chemotherapies, radiation treatments, and immunomodulatory therapies. A number of ongoing trials continue the push toward finding a broadly applicable and efficient therapy for patients with HGG.

\section{References}

1. Louis DN, Perry A, Reifenberger G, et al. The 2016 World Health Organization Classification of Tumors of the Central Nervous System: a summary. Acta Neuropathol. 2016;131(6): 803-820.

2. Stupp R, Mason WP, van den Bent MJ, et al. Radiotherapy plus concomitant and adjuvant temozolomide for glioblastoma. N Engl J Med. 2005;352(10):987-996.
3. Lawler SE. Cytomegalovirus and glioblastoma; controversies and opportunities. J Neurooncol. 2015;123(3):465-471.

4. Kelly E, Russell SJ. History of oncolytic viruses: genesis to genetic engineering. Mol Ther. 2007;15(4):651-659.

5. Martuza RL, Malick A, Markert JM, et al. Experimental therapy of human glioma by means of a genetically engineered virus mutant. Science. 1991;252(5007):854-856.

6. Bischoff JR, Kirn DH, Williams A, et al. An adenovirus mutant that replicates selectively in p53-deficient human tumor cells. Science. 1996;274(5286):373-376.

7. Foreman PM, Friedman GK, Cassady KA, Markert JM. Oncolytic virotherapy for the treatment of malignant glioma. Neurotherapeutics. 2017;14(2):333-344.

8. Desai K, Hubben A, Ahluwalia M. Combination of oncolytic viruses and immune checkpoint inhibitors in glioblastoma. Glioma. 2019;2(1):7-19.

9. Lim M, Weller M, Chiocca EA. Current state of immunebased therapies for glioblastoma. Am Soc Clin Oncol Educ Book. 2016;35:e132-e139.

10. Hulou MM, Cho CF, Chiocca EA, Bjerkvig R. Experimental therapies: gene therapies and oncolytic viruses. Handb Clin Neurol. 2016;134:183-197.

11. Csatary LK, Bakács T. Use of Newcastle disease virus vaccine $(\mathrm{MTH}-68 / \mathrm{H})$ in a patient with high-grade glioblastoma. JAMA. 1999;281(17):1588-1589.

12. Csatary LK, Gosztonyi G, Szeberenyi J, et al. MTH-68/H oncolytic viral treatment in human high-grade gliomas. $J$ Neurooncol. 2004;67(1-2):83-93.

13. Patel DM, Foreman PM, Nabors LB, et al. Design of a phase I clinical trial to evaluate M032, a genetically engineered HSV-1 expressing IL-12, in patients with recurrent/progressive glioblastoma multiforme, anaplastic astrocytoma, or gliosarcoma. Hum Gene Ther Clin Dev. 2016;27(2):69-78.

14. Cloughesy T, Petrecca K, Walbert T, et al. Toca 511 \& Toca FC versus standard of care in patients with recurrent high grade glioma. Neuro Oncol. 2019;21(suppl 6):vi284.

15. Cloughesy TF, Landolfi J, Hogan DJ, et al. Phase 1 trial of vocimagene amiretrorepvec and 5-fluorocytosine for recurrent high-grade glioma. Sci Transl Med. 2016;8(341): 341 ra75.

16. Cloughesy TF, Landolfi J, Vogelbaum MA, et al. Durable complete responses in some recurrent high-grade glioma patients treated with Toca 511 + Toca FC. Neuro Oncol. 2018; 20(10):1383-1392.

17. Moher D, Liberati A, Tetzlaff J, Altman DG. Preferred reporting items for systematic reviews and meta-analyses: the PRISMA statement. PLoS Med. 2009;6(7):e1000097.

18. Harrow S, Papanastassiou V, Harland J, et al. HSV1716 injection into the brain adjacent to tumour following surgical resection of high-grade glioma: safety data and long-term survival. Gene Ther. 2004;11(22):1648-1658.

19. Coen DM, Goldstein DJ, Weller SK. Herpes simplex virus ribonucleotide reductase mutants are hypersensitive to acyclovir. Antimicrob Agents Chemother. 1989;33(8):1395-1399.

20. Rampling R, Cruickshank G, Papanastassiou V, et al. Toxicity evaluation of replication-competent herpes simplex virus (ICP 34.5 null mutant 1716) in patients with recurrent malignant glioma. Gene Ther. 2000;7(10):859-866.

21. Papanastassiou V, Rampling R, Fraser M, et al. The potential for efficacy of the modified (ICP 34.5(-)) herpes simplex virus HSV1716 following intratumoural injection into human malignant glioma: a proof of principle study. Gene Ther. 2002;9(6):398-406.

22. Markert JM, Medlock MD, Rabkin SD, et al. Conditionally replicating herpes simplex virus mutant, G207 for the treatment of malignant glioma: results of a phase I trial. Gene Ther. 2000;7(10):867-874.

23. Forsyth P, Roldán G, George D, et al. A phase I trial of intratumoral administration of reovirus in patients with histo- 
logically confirmed recurrent malignant gliomas. Mol Ther 2008;16(3):627-632.

24. Markert JM, Razdan SN, Kuo HC, et al. A phase 1 trial of oncolytic HSV-1, G207, given in combination with radiation for recurrent GBM demonstrates safety and radiographic responses. Mol Ther. 2014;22(5):1048-1055.

25. Todo T. Oncolytic virus therapy using genetically engineered herpes simplex viruses. Front Biosci. 2008;13:2060-2064.

26. Fukuhara H, Ino Y, Todo T. Oncolytic virus therapy: a new era of cancer treatment at dawn. Cancer Sci. 2016;107(10): 1373-1379.

27. Ning J, Wakimoto H. Oncolytic herpes simplex virus-based strategies: toward a breakthrough in glioblastoma therapy. Front Microbiol. 2014;5:303.

28. Kambara H, Okano H, Chiocca EA, Saeki Y. An oncolytic HSV-1 mutant expressing ICP34.5 under control of a nestin promoter increases survival of animals even when symptomatic from a brain tumor. Cancer Res. 2005;65(7):2832-2839.

29. Lang FF, Conrad C, Gomez-Manzano C, et al. Phase I Study of DNX-2401 (Delta-24-RGD) Oncolytic Adenovirus: Replication and Immunotherapeutic Effects in Recurrent Malignant Glioma. J Clin Oncol. 2018;36(14):1419-1427.

30. Nakamizo A, Marini F, Amano T, et al. Human bone marrow-derived mesenchymal stem cells in the treatment of gliomas. Cancer Res. 2005;65(8):3307-3318.

31. Duarte S, Carle G, Faneca H, et al. Suicide gene therapy in cancer: where do we stand now? Cancer Lett. 2012;324(2): 160-170.

32. Halloran PJ, Fenton RG. Irreversible G2-M arrest and cytoskeletal reorganization induced by cytotoxic nucleoside analogues. Cancer Res. 1998;58(17):3855-3865.

33. Wei SJ, Chao Y, Hung YM, et al. S- and G2-phase cell cycle arrests and apoptosis induced by ganciclovir in murine melanoma cells transduced with herpes simplex virus thymidine kinase. Exp Cell Res. 1998;241(1):66-75.

34. Rainov NG. A phase III clinical evaluation of herpes simplex virus type 1 thymidine kinase and ganciclovir gene therapy as an adjuvant to surgical resection and radiation in adults with previously untreated glioblastoma multiforme. Hum Gene Ther. 2000;11(17):2389-2401.

35. Westphal M, Ylä-Herttuala S, Martin J, et al. Adenovirusmediated gene therapy with sitimagene ceradenovec followed by intravenous ganciclovir for patients with operable highgrade glioma (ASPECT): a randomised, open-label, phase 3 trial. Lancet Oncol. 2013;14(9):823-833.

36. Wheeler LA, Manzanera AG, Bell SD, et al. Phase II multicenter study of gene-mediated cytotoxic immunotherapy as adjuvant to surgical resection for newly diagnosed malignant glioma. Neuro Oncol. 2016;18(8):1137-1145.

37. Ji N, Weng D, Liu C, et al. Adenovirus-mediated delivery of herpes simplex virus thymidine kinase administration improves outcome of recurrent high-grade glioma. Oncotarget. 2016;7(4):4369-4378.

38. Brenner AJ, Cohen YC, Vredenburgh JJ, et al. Ofranogene obadenovec (VB-111), an anti-cancer gene therapy in combination with bevacizumab to improve overall survival compared to bevacizumab monotherapy in patients with rGBM: a phase 2 historically controlled trial. J Clin Oncol. 2016; 34(15)(suppl):2074.

39. Cloughesy T, Brenner AJ, Butowski N, et al. ATIM-19. Results of the GLOBE study: a phase 3, randomized, controlled, double-arm, open-label, multi-center study of VB-111 combined with bevacizumab vs. bevacizumab monotherapy in patients with recurrent glioblastoma. Neuro Oncol.2018; 20(suppl 6):vi4-vi5.

40. Markert JM, Liechty PG, Wang W, et al. Phase Ib trial of mutant herpes simplex virus G207 inoculated pre-and posttumor resection for recurrent GBM. Mol Ther. 2009;17(1): 199-207.
41. Okaji Y, Tsuno NH, Tanaka M, et al. Pilot study of antiangiogenic vaccine using fixed whole endothelium in patients with progressive malignancy after failure of conventional therapy. Eur J Cancer. 2008;44(3):383-390.

42. Chiocca EA, Abbed KM, Tatter S, et al. A phase I open-label, dose-escalation, multi-institutional trial of injection with an E1B-attenuated adenovirus, ONYX-015, into the peritumoral region of recurrent malignant gliomas, in the adjuvant setting. Mol Ther. 2004;10(5):958-966.

43. Samson A, Scott KJ, Taggart D, et al. Intravenous delivery of oncolytic reovirus to brain tumor patients immunologically primes for subsequent checkpoint blockade. Sci Transl Med. 2018;10(422):eaam7577.

44. Kicielinski KP, Chiocca EA, Yu JS, et al. Phase 1 clinical trial of intratumoral reovirus infusion for the treatment of recurrent malignant gliomas in adults. Mol Ther. 2014;22(5): $1056-1062$.

45. Freeman AI, Zakay-Rones Z, Gomori JM, et al. Phase I/II trial of intravenous NDV-HUJ oncolytic virus in recurrent glioblastoma multiforme. Mol Ther. 2006;13(1):221-228.

46. Geletneky K, Hajda J, Angelova AL, et al. Oncolytic H-1 Parvovirus shows safety and signs of immunogenic activity in a first phase I/IIa glioblastoma trial. Mol Ther. 2017;25(12): 2620-2634.

47. Desjardins A, Gromeier M, Herndon JE II, et al. Recurrent glioblastoma treated with recombinant poliovirus. $N$ Engl J Med. 2018:379(2):150-161.

48. Immonen A, Vapalahti M, Tyynelä K, et al. AdvHSV-tk gene therapy with intravenous ganciclovir improves survival in human malignant glioma: a randomised, controlled study. $\mathrm{Mol}$ Ther. 2004;10(5):967-972.

49. Colombo F, Barzon L, Franchin E, et al. Combined HSV-TK/ IL-2 gene therapy in patients with recurrent glioblastoma multiforme: biological and clinical results. Cancer Gene Ther. 2005;12(10):835-848.

50. Prados MD, McDermott M, Chang SM, et al. Treatment of progressive or recurrent glioblastoma multiforme in adults with herpes simplex virus thymidine kinase gene vector-producer cells followed by intravenous ganciclovir administration: a phase I/II multi-institutional trial. J Neurooncol. 2003; 65(3):269-278.

51. Voges J, Reszka R, Gossmann A, et al. Imaging-guided convection-enhanced delivery and gene therapy of glioblastoma. Ann Neurol. 2003;54(4):479-487.

52. Shand N, Weber F, Mariani L, et al. A phase 1-2 clinical trial of gene therapy for recurrent glioblastoma multiforme by tumor transduction with the herpes simplex thymidine kinase gene followed by ganciclovir. GLI328 European-Canadian Study Group. Hum Gene Ther. 1999;10(14):2325-2335.

53. Klatzmann D, Valéry CA, Bensimon G, et al. A phase I/II study of herpes simplex virus type 1 thymidine kinase "suicide" gene therapy for recurrent glioblastoma. Hum Gene Ther. 1998;9(17):2595-2604.

54. Ram Z, Culver KW, Oshiro EM, et al. Therapy of malignant brain tumors by intratumoral implantation of retroviral vector-producing cells. Nat Med. 1997;3(12):1354-1361.

55. Chiocca EA, Yu JS, Lukas RV, et al. Regulatable interleukin-12 gene therapy in patients with recurrent high-grade glioma: Results of a phase 1 trial. Sci Transl Med. 2019; 11(505):eaaw5680.

56. Chiocca EA, Aguilar LK, Bell SD, et al. Phase IB study of gene-mediated cytotoxic immunotherapy adjuvant to up-front surgery and intensive timing radiation for malignant glioma. J Clin Oncol. 2011;29(27):3611-3619.

57. Chiocca EA, Smith KM, McKinney B, et al. A phase I trial of Ad.hIFN-beta gene therapy for glioma. Mol Ther. 2008; 16(3):618-626.

58. Cornetta K, Croop J, Dropcho E, et al. A pilot study of doseintensified procarbazine, CCNU, vincristine for poor prog- 
nosis brain tumors utilizing fibronectin-assisted, retroviralmediated modification of CD34+ peripheral blood cells with O6-methylguanine DNA methyltransferase. Cancer Gene Ther. 2006;13(9):886-895.

59. Lang FF, Bruner JM, Fuller GN, et al. Phase I trial of adenovirus-mediated p53 gene therapy for recurrent glioma: biological and clinical results. J Clin Oncol. 2003;21(13): 2508-2518.

60. Germano IM, Fable J, Gultekin SH, Silvers A. Adenovirus/ herpes simplex-thymidine kinase/ganciclovir complex: preliminary results of a phase I trial in patients with recurrent malignant gliomas. J Neurooncol. 2003;65(3):279-289.

61. Smitt PS, Driesse M, Wolbers J, et al. Treatment of relapsed malignant glioma with an adenoviral vector containing the herpes simplex thymidine kinase gene followed by ganciclovir. Mol Ther. 2003;7(6):851-858.

62. Sandmair AM, Loimas S, Puranen P, et al. Thymidine kinase gene therapy for human malignant glioma, using replicationdeficient retroviruses or adenoviruses. Hum Gene Ther. 2000; 11(16):2197-2205.

63. Trask TW, Trask RP, Aguilar-Cordova E, et al. Phase I study of adenoviral delivery of the HSV-tk gene and ganciclovir administration in patients with current malignant brain tumors. Mol Ther. 2000;1(2):195-203.

64. Qureshi NH, Bankiewicz KS, Louis DN, et al. Multicolumn infusion of gene therapy cells into human brain tumors: technical report. Neurosurgery. 2000;46(3):663-669.

65. Palù $\mathrm{G}$, Cavaggioni $\mathrm{A}, \mathrm{Calvi} \mathrm{P}$, et al. Gene therapy of glioblastoma multiforme via combined expression of suicide and cytokine genes: a pilot study in humans. Gene Ther. 1999; 6(3):330-337.
66. Colombo F, Zanusso M, Casentini L, et al. Gene stereotactic neurosurgery for recurrent malignant gliomas. Stereotact Funct Neurosurg. 1997;68(1-4 Pt 1):245-251.

67. Puumalainen AM, Vapalahti M, Agrawal RS, et al. Beta-galactosidase gene transfer to human malignant glioma in vivo using replication-deficient retroviruses and adenoviruses. Hum Gene Ther. 1998;9(12):1769-1774.

\section{Disclosures}

The authors report no conflict of interest concerning the materials or methods used in this study or the findings specified in this paper.

\section{Author Contributions}

Conception and design: Wang. Acquisition of data: all authors. Analysis and interpretation of data: all authors. Drafting the article: all authors. Critically revising the article: all authors. Reviewed submitted version of manuscript: all authors. Approved the final version of the manuscript on behalf of all authors: Wang. Administrative/technical/material support: Elder. Study supervision: Wang, Elder.

\section{Correspondence}

Joshua L. Wang: The Ohio State University College of Medicine, Columbus, OH. joshua.wang@osumc.edu. 